Volume 6, Issue 2 (2021), pp. 99-106

Journal of School Administration Research and Development

ISSN: 2470-8496 Print/ ISSN: 2470-850X Online

ojed.org/jsard

\title{
How Did We Get Here? One District's Approach to Device Assisted Learning Technology Implementation
}

\author{
Cailen M. O'Shea \\ North Dakota State University, USA \\ Guy Trainin \\ University of Nebraska-Lincoln, USA
}

\begin{abstract}
The COVID-19 pandemic necessitated the importance of online and device-assisted learning. What was demonstrated at this time was how prepared districts were to make this transition. Lincoln Public Schools, in Lincoln, Nebraska, was one district that successfully planned and implemented device-assisted learning technology into their school system ahead of the pandemic. This study sought to better understand the process that district leadership enacted to inform practice on developing a technology plan and its implementation. The study's findings show that five key elements are required for successful replication: (a) shared goals, (b) right people and right-fit, (c) cross-communication, (d) implementation, and (e) growth and support. This article serves as a practitioner's guide to implementation as many districts across the country are still trying to figure out how best to serve their students and families.
\end{abstract}

Keywords: technology, device-assisted learning

Amid the challenges and changes presented from the Covid-19 pandemic, schools and communities have been working together to find ways to ensure students have access to the curriculum, their teachers, and their peers. Schools and families were thrown into crisis distance learning where delivery of instruction ranged from new online platforms to tremendous packets of work being picked up weekly at the schools. The pandemic presented a unique problem for schools and communities as it impacted them similarly across the board. Public schools, private schools, rural, and urban schools alike were in an unprecedented situation where they needed to support and direct student learning from afar. Where schools differed was in their district and community supports. Some schools found themselves ill-prepared for the major transition, while others were better situated. This was especially true following the recession of 2008. Schools and communities were hit hard by this recession which made allocating monies to future technology initiatives a significant barrier for many districts.

The significance of a district's technology plan may have been overlooked before, but the differences between districts with strong technology programs and those without were made clear due to the pandemic. Technology planning in schools can be complex and nuanced (Vanderlinde \& van Braak, 2012), and the pandemic highlighted the differences between ill-prepared and well-situated schools' ability to adapt. The lack of a strong plan was one component that further exacerbated the digital divide, which impacts students across the country. Tomer and colleagues (2020) explain that more than fifteen million children, the majority of whom are Latinx, Black, or Native American, lacked adequate internet access. Large pockets of rural and urban students and teachers live in digital deserts where consistent access to the internet, which is seen by many as an essential human right (Feldstein, 2017), is not possible (Tomer et al., 2020). While the digital divide does not completely rest with a school district, many students, teachers, and families found themselves in precarious situations when the shift to online learning began as their district had not yet been able to make significant 
progress towards technology integration. However, districts were best able to adapt to the challenges of the pandemic when they had a more developed and robust infrastructure (Canese \& Amarilla, 2020).

In 2018, the second-largest school district in Nebraska, Lincoln Public Schools was named "Champion for Computer Science" by The Computer Science Teachers Association and code.org. What did Lincoln Public Schools do to move to the front of the country regarding technology? Could the work being done in this district be replicated by other school districts?

\section{METHOD}

The purpose of this article is to inform practice on the development of a technology plan and its implementation. The work is grounded in the International Society for Technology in Education (ISTE) standards for educational leaders, specifically, standard four: systems designers. The ISTE framework for systems designers highlights the need to collaboratively establish robust infrastructure and systems needed to implement the strategic plan. For this bounded case study, we purposely selected members of the district leadership team. We chose a bounded study as we decided to focus on a single entity (Merriam, 2009), in this case, the school district. We focused on studying key participants with key involvement in the process. We wanted to ensure that the information gleaned from each participant would speak directly to the decisions made and the path followed. In doing so, we asked members of the district leadership team to point us in the direction of those who were heavily involved in the process. Each interview concluded by asking the participant who they thought we should talk to next. This snowball sampling method allowed us to identify participants from unexpected areas of influence, such as the department of business affairs. Our sample includes nine participants in positions, including the superintendent, associate superintendent, chief technology officer, a member of the board of education, curriculum director, and principal.

To better ensure reliability and credibility, the interviews were transcribed and uploaded into Nvivo 10 for analysis. The interviews utilized a mix of a prirori codes developed in partnership between the two researchers and the literature on technology planning and infrastructure (Miles et al., 2013; Yin, 2013). Coding was done in conjunction to develop shared operational definitions, and detailed quotes were used to illustrate a full range of participants' perceptions (Creswell \& Poth, 2017). Through purposely interviewing multiple leadership team members in the school district and asking them to member check the results, we were able to identify a more holistic approach that led to the successful development and implementation in this district.

In mapping the work this way, we collaboratively developed a template to guide technology implementation in other districts. In this process, we identify five key elements: (a) shared goals, (b) right people and right-fit, (c) crosscommunication, (d) implementation, and (e) growth and support. Each component is described in the following sections, followed by a brief grounding in the literature and a model for replication with attention to the process's challenges along the way. We aim to answer the research question: what elements are needed for successful school district technology planning and implementation?

\section{About the District}

Lincoln public schools are the second largest in Nebraska, with over 42,000 total students (LPS, 2018). As a district, it has seen recent and considerable growth, with about 3,000 students from the 1998-1999 school year $(31,100)$ to the 20082009 school year $(34,001)$, which is about $10 \%$ - followed by another surge that took place between the 2008-2009 school year and the 2018-2019 school year as the district increased by 8,000 students or about $23 \%$. Coincidentally, the peak in student growth happened during the technology initiative, adding complexity and urgency to the plans.

The student make-up of the district is comparable to the state average. This district has $33.5 \%$ of students identifying as underrepresented populations, $46 \%$ qualified for free or reduced-price lunch, and $7 \%$ of students are English language learners (ELL). These averages are slightly higher than the state averages of 27\% (Nebraska State Demographics, 2018) underrepresented populations status, $44 \%$ qualifying for free or reduced lunch, and 6\% ELL.

\section{FINDINGS}

\section{Element 1: Shared Goals}

The progression that led to the award in 2018 began in 2010 when the district embarked on a path into the future by creating a strategic plan. The strategic plan included a focus on a built-out education initiative where the implementation 
began utilizing viable digital curriculum and tools at one school as a pilot and then spreading it throughout the district. District leaders explained that the educational landscape was changing and that teaching students must happen through technology. Several participants mentioned that they wanted to see teachers using technology in ways that could enhance student learning. One participant reported: "technology is not here to just replace the textbook. It's here to afford teachers to do things that they could not do before, or at least not do easily" (Personal communication, 2018).

While administrators and educators within the district widely supported the built-out education plan, the plan needed community support, politically and financially. Coming on the heels of the 2008 recession, it was clear that leaders and voters were wary of new significant investments. Even though technology integration had been increasing in many schools, it could not be assumed that parents and community members would see this as a positive change. The leadership team at the district decided to survey community members and key stakeholders to understand how the public perceived the district's use of technology. The survey results were unequivocal. The community believed that technology was underutilized and that a more comprehensive approach to 21 st-century learning was needed. Stakeholders wanted a technology plan and were willing to support it. The response led to developing a technology committee consisting of teachers, administrators, associate superintendents, and community members to develop a comprehensive technology plan to fit the district. The participants explained that a goal of the leadership team would be to ensure that all stakeholders had a voice and a vehicle to move agenda items in an organized way.

In line with the work of Robertson and Corrigan (2018), a collaborative approach to decision-making for school districts can support technology implementation. As such, schools must communicate and value community input and seek out those who might be underrepresented. This can be done by surveying community members and other engagement initiatives.

\section{Element 2: Right People Right Fit}

Now that the leadership had the community's support, the committee faced the next problem, where to begin? The district employs almost 8,000 people, 183 administrators, and 59 of whom work at the district office in area-specific roles such as curriculum director, assessment/evaluation specialists, and associate superintendents. Participants reported that a challenge of having a large school district is to find a way to engage stakeholders while moving at a reasonable pace and allowing other initiatives to continue. The goal was to enhance student learning in and through technology, so everyone involved needed to have a say.

To meet these needs, district leadership needed to consider multiple practical and theoretical collaborations. Voices from every aspect of the school system needed attention. The right people were required to bring together ideas while advocating for their respective departments. Each department not only needed representation but their input on future directions and needs. Participants explained that bringing together these goals meant having people who could work together while advocating for their department. This melting pot of ideas and concerns meant that pressure was high and positive collaboration was required. Members of this committee needed to work together to better the district even if their department's goals were not directly being met. This mesh of people and ideas brought about the district technology committee.

Participants explained that the committee first decided to add a curriculum specialist focused on computer science. This role served as a member of the curriculum department. Creating this lead role in computer science required finding the right "evangelist." It also required the technology department to give up a position. This collaboration between departments demonstrates how each felt about the need for the position. Housing the role in the curriculum department allowed the focus of the role to remain on instruction. As one participant mentioned, having the role stay in the curriculum department gave the process a strong curriculum and instruction connection. This connection allowed the committee a springboard for future work.

The ISTE standard 4d explains the importance of partnerships that support strategic vision, achieve learning priorities, and improve operations. School leaders can help develop a collaborative environment amenable to change and demonstrate this leadership philosophy to consider the district's goal instead of one department's goals.

\section{Element 3: Cross-Communication}

One issue brought up by almost every participant we talked to was cross-communication. We use the term crosscommunication to highlight that communication went beyond established hierarchical communication. It shows how departments that tended to work independently now needed to align their actions. The instruction department and the technology department needed tenable justification and coordination for every action. While this linkage seems intuitive 
enough, it proved to be a challenge. This was not due to a lack of collegiality on behalf of the stakeholders, but more so due to each department's different needs and emphases. Multiple participants echoed this sentiment, but one salient example of this tension was expressed by a participant who explained that "what gets all the attention is the technology, and that gets the spotlight, and that puts other people on the spot who feel like we aren't getting our just due in making decisions and so on" (Personal communication, 2018). 11 participants expressed the idea that the technology plan was not to simply get more devices into the classrooms but that the devices are there to enhance each student's learning. The Chief Technology Officer had this to say about acting as a conduit between departments: "Those who are either all on one side or the other (technology or instruction) probably are not doing as much for their institution as their institution needs" (Personal communication, 2018). Overall, the committee realized that they needed to work across departments to be successful.

Cross-communication was a significant component for successful implementation as it required a degree of giving and take. Focusing on collaboration recognizes the school's constructive power to promote student success and well-being (Preston \& Barnes, 2017). School leaders need to bring team members together to understand the shared vision for technology implementation.

\section{Element 4: Right Tools for the Job}

Once departments decided how the technology could support instruction, the next step of the initiative was deciding what devices should be used and how they get these devices to students. The participants explained that they looked at several devices, including tablets, Chromebooks, and generic laptops. Each device had pros and cons. The issue found with the iPad was the functionality. There are many things that an iPad can do, but the lack of a keyboard and price tag made it a difficult sell. MacBook's were the next logical progression. Teachers in the district had been issued a MacBook, and most classrooms utilized airplay to project. Teachers were knowledgeable of their computers and would likely be able to troubleshoot easily.

The physical sustainability of the devices was also a concern. Chromebooks were cheaper than their Mac counterparts, but they did break like any computer, especially when in the hands of 8-year-olds. One strategy for future support was leasing the devices out from companies. Spokane Public Schools (SPS), a school district of similar size, addressed this by leasing their technology. The issue with this model was the inconsistency. There was no apparent plan for the amount a school might need five years down the line. With a growing school district, the leadership team decided this was not the right path. When asked about funding an initiative like this with the future in mind, several participants mentioned that the technology committee had built a "war chest" of funds. The committee knew that they needed to have a lump sum of money to buy the first round of devices but needed to support the initiative down the line.

The committee eventually decided on Chromebooks. This decision was partly due to the district's plan to utilize google drive as a web-based platform for student work. Without the need for the student computers to store all of the information, Chromebooks offered all of a MacBook's benefits without the hefty price tag.

The next part of the implementation meant deciding upon where this device-assisted learning initiative took place physically. Participants noted that initially, it seemed as though the high schools in the district would make the most sense. Older kids know more about technology, are more developmentally ready to use technology independently, and are closer to the workforce age, where many technical skills are expected. As pointed out by the curriculum director, there was a significant problem with using ninth graders as the entry point for this plan:

A challenge with high school is there are very few classes with just ninth graders. So, if you begin with ninth grade as your entry point, what does the Spanish II teacher do when half their class comprises sophomore and juniors who are without this device? That is going to be incredibly disruptive to teachers. It will be really difficult to start with ninth graders and work your way up.

Another option discussed was starting this process in the elementary schools. If students "grew up" with certain technology, they wouldn't need to go through the secondary change that their older peers might. The devices and digital curriculum would follow the students for their careers while in the district. With these two starting points being discussed, the district chose to start their device-assisted learning initiative in their middle schools with sixth graders. The middle school math curriculum had recently moved to a digital platform. They choose middle school as a starting point to let their curriculum drive their planning for what devices they use and how they enact the plan. The director of the curriculum explained: "We wanted to be early in the conversations... we wanted to be the catalyst for some of the change, we didn't want to be playing catch up and be scrambling to find a digital curriculum while devices were sitting in a classroom" (Personal communication, 2018). A pilot school had been selected, and the initiative began. Feedback from teachers, 
students, and administrators of this pilot school was used to shape the rest of the initiative's work. In the following years, elementary students in grades 3-5 and high school students were given Chromebooks as the initiative grew.

The district then developed a process for adopting applications and software. There were plenty of applications that teachers and students were already using. The free price tag made some of the applications especially intriguing. At the onset of the initiative, teachers could pick and download apps on any school device with their credentials. This freedom was ideal for teachers. If they found a chrome extension or app, they liked they could download it to their student's devices immediately. In return, most programs only requested student account information. With the number of vendors seemingly growing exponentially, it was quickly realized that the process of adopting software needed to be handled by the central office so that the cost can be controlled, privacy could be protected, and support could be organized. The district decided to manage all student devices from district-level user accounts. This meant that the technology committee would be in charge of which programs would be adopted. The apps could be "pushed" to student devices or accessed from a matrix of approved programs. Teachers and school leaders could submit request tickets if they found a program they wanted to be approved for their students.

Approving software and apps included multiple departments such as computing services, curriculum, library media, special education, and assessment and evaluation. People spent hours upon hours reviewing tools before making decisions about their appropriateness and usefulness with students. As one participant put it, "This level of cooperation was essential to make sure of a thorough review of these tools. The commitment of those committee members was pretty significant" (Personal communication, 2018).

Educational leaders need to consider the cost of technology infusion and the pedagogical decision-making as well as protecting students' privacy (Huang et al., 2019). A technology committee or centralized decision-making team can allow for more strategic planning.

\section{Element 5: Growth and Support}

One main channel for innovation for the district was professional development. Teachers needed to learn how to enhance their lessons with the new technology while learning how Chromebooks operated. Several participants noted that this need for professional development was critical for teachers but was challenging the central office staff. Teachers were being asked to make a second-order shift and move from a paper-based curriculum to online platforms. This shift presented the district with a pedagogical opportunity to enhance student learning. The district then focused its professional development with these ideas in mind.

The solution was a focus on a dedicated Instructional Technology Coach in each building. LPS supplied each school with a .5 Full-Time Employee. Some schools decided to share coaches, while others found areas in their budget to support the other .5 required for a full-time employee. These coaches were tasked with helping teachers develop lessons and comfort the technology through instructional rounds and modeling. Participants reported that the district wanted boots on the ground to help teachers and administrators change to device-assisted learning. This long-term support model system was designed along the lines of organizational learning theory, where the learning processes are connected to organizational support sources (e.g., coaches, cadres, lesson treatments, etc.) that are available within a district and school.

\section{Challenges}

A second-order change that transforms a group's function in an organization from what it has traditionally done to a more expansive role (Marzano et al., 2005) adds complications for all organization members. This was a worry for the technology committee as participants explained that there was a fear that parents would be resistant to this type of change. Parents' interaction with students changed from digging in their kids' backpacks to find the necessary information online. This meant that parents needed access to see how their children were progressing. This parental understanding was also contingent upon teachers getting information online. As one participant put it:

Outreach to parents is digital, so we need to reorient students, parents, teachers, and leaders to ensure everyone has access to instructional materials. They have clarity into how we use those materials. Adapting instructional delivery to leveraging digital tools isn't as easy as simply giving them the digital tools. They have to have them in the first place; that is a necessary condition.

Challenges reached beyond the parents as well. One topic was brought up by two sets of participants focused on dealing with educational vendors. One participant noted, "A major challenge from the curriculum side was that vendors and publishers oversell and under deliver" (Personal communication, 2018). The publishers and vendors know what the districts and schools want. Still, sometimes they are not readily capable of delivering that. One such issue arose with a 
vendor who had licenses issued for all students but did not consider that some students move schools but remain in the district.

Other issues with vendors included student privacy and advertising. Some web-based applications wanted access to a student's entire profile. While this was an easy click for students, it meant that their private data could be shared without them knowing, which would place LPS in violation of the Family Educational Rights and Policy Act (FERPA). Advertising was also a challenge because any ad, even a placid one, could still be broadcast to 42,000 impressionable students. Several participants noted that protection of privacy was a considerable obstacle, especially when moving forward. Access to students was in high demand and having a system to follow for decision-making was imperative.

As per Shernoff et al. (2017), many teachers believe that technology integration is necessary for developing integrated approaches to education, but they do not feel we are prepared to implement them. Educational leaders need to adhere to reciprocal accountability where with every increment of performance they expect from teachers, they have an equal responsibility to provide teachers with the capacity to meet that expectation (Abelmann et al., 1999).

\section{Replication}

The identified five elements of this initiative offer a strong guideline for replication. If a district is considering developing a more enhanced device-assisted technology program, they should consider each of these components and how it would make the most sense for implementation in their district (see Figure 1).

- Shared Goals- To begin this process, a district needs buy-in from all concerned parties. Parents, teachers, staff, and community members all need to understand the need associated with the initiative. Interviews, surveys, and town halls are all ways to find out what the community is invested in.

- Right People Right Fit- Relationships are critical in every aspect of education. Finding the right people to work together for the common good of the district is paramount to success. As an educational leader, it is necessary to select people who can work together to better the school system and not just their department.

- Cross-Communication- Even in a small district, those moving the initiative along need to be in constant communication with each other. Decision-making should be shared as evenly as possible. The implementation goals need to be seen as goals for everyone and constantly be the topic of the conversation. "What are we all doing to reach our goal?"

- Right Tools for the Job- Decide where, when, and how the devices will be distributed. Let the curriculum drive decision-making. It is fair to look at similar districts for guidance. Schools may be willing to share the vendors they used and even about the contracts they have.

- Growth and Support- There needs to be sustainable fiscal support, "a one-time infusion of capital is a recipe for disaster" (Personal communication, 2018). Teachers are not the only ones who will need support with these changes. Parents and students need support as well. Online videos can be uploaded to YouTube, beginning of the year activities are great ways to help scaffold community members.

\section{CONCLUSION}

The main purpose of this article is to inform practice. The findings from this study echo the research of Vanderlinde \& van Braak (2012) that technology planning in schools is complex and nuanced. The technology implementation at the district involved in the study was done to present a model for other school districts to follow. In smaller districts, for example, the need for device-assisted learning might be just as great as it was in this one. Still, it might be difficult for them to develop their implementation plan without similar structural supports. The replication model is not meant to be considered the only way of enacting a technology plan; but rather, a foundation for other schools to learn from this district's trials and errors while considering their specific context. This planning is aligned with the work of Shernoff et al. (2017) that teachers are interested in utilizing integrated approaches, but they need more support to implement them. Schools need to make adjustments to the needs of their communities and students specifically. The figure below (Figure 1) shows the process identified through our interviews, analyzing the data, and member-checking with participants. These are the five areas we believe need to be included for a technology implementation process to be effective. Though it follows an iterative process, different schools can be situated at different starting points. It is important to note that revisiting each component is critical to continued effective implementation. 


\section{Figure 1}

\section{Five Elements of Initiative}

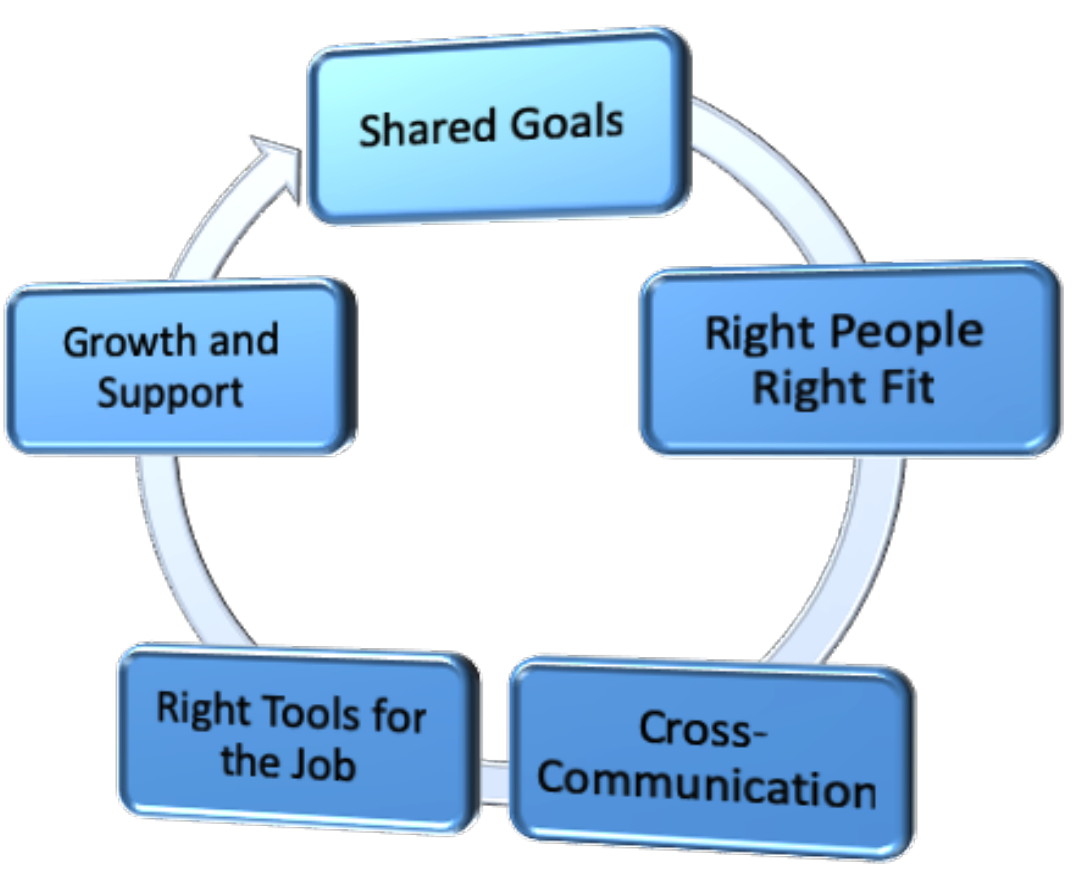

REFERENCES

Abelmann, C., R. Elmore, J. Even, S. Kenyon, and J. Marshall. 1999. When accountability knocks, will anyone answer? RR-42. Philadelphia, PA: Consortium for Policy Research in Education.

Canese, V., \& Amarilla, J. (2020). Educational administrators' facing COVID-19 measures in Paraguay. Journal of Educational Technology Development and Exchange, 13(1), 1-15.

Creswell, J. W., \& Poth, C. N. (2017). Qualitative inquiry and research design: Choosing among five approaches. 4th ed. Los Angeles.

Feldstein, S. (2017). Why internet access is a human right: What we can do to protect it. Available at SSRN 2982165. Huang, R., Spector, J. M., \& Yang, J. (2019). Educational Technology a Primer for the 21st Century. Springer.

LPS. Demographics [Data Set]. https://docushare.lps.org/docushare/dsweb/Get/Document2505088/2018\%202019\%20Student\%20Section.pdf

Marzano, R., Waters, T., \& McNulty, B. (2005). School leadership that works. From research to results. Aurora, Colorado: McREL.

Merriam, S. B. (2009). Qualitative research: A guide to design and implementation. Jossey-Bass.

Miles, M. B., Huberman, A. M., \& Saldaña, J. (2013). Qualitative data analysis: A methods sourcebook. SAGE Publications, Incorporated.

Nebraska State. Demographics [Data Set]. http://nep.education.ne.gov/State?DataYears=20152016

Preston, J. P., \& Barnes, K. E. (2017). Successful leadership in rural schools: Cultivating collaboration. Rural Educator, 38(1), 6-15.

Robertson, L., \& Corrigan, L. (2018). Networking research, policy and practice: Designing a district technology plan through collaborative professionalism. Systemics, Cybernetics, and Informatics, 16(4).

Tomer A, Fishbane L, Siefer A, Callahan B. (2020). Digital prosperity: How broadband can deliver health and equity to all communities in Metropolitan Infrastructure Initiative. Brookings Institution. https://www.brookings.edu/research/digitalprosperity-how-broadband-can-deliver-healthand-equity-to-allcommunities/. 
Vanderlinde, R., \& van Braak, J. (2012). Technology planning in schools: An integrated research-based model. British Journal of Educational Technology, 44(1), E14-E17.

Yin, R. K. (2013). Case study research: Design and methods. SAGE Publications.

CAILEN M. O'SHEA, PhD, is an assistant professor in the school of education at North Dakota State University His major research interests lie in school transformation and equitable instructional leadership. Email: cailen.oshea@ndsu.edu

GUY TRAININ, PhD, is a professor of Education at the University of Nebraska-Lincoln. He focuses his research in the areas of reading, innovative schooling, teacher education, and literacy integration with technology and the Arts. Email: gtrainin2@unl.edu

Manuscript submitted: January 27, 2021

Manuscript revised: April 2, 2021

Manuscript revised: May 23, 2021

Accepted for publication: July 22, 2021 